\title{
Antioxidants in Pinus Pinaster roots and mycorrhizal fungi during the early steps of symbiosis
}

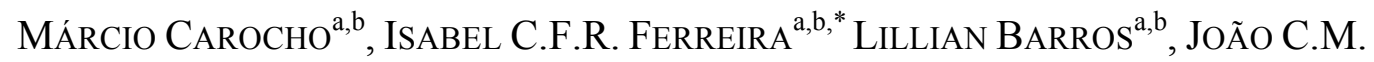

$$
\text { BARREIRA }^{\mathrm{a}, \mathrm{b}}, \text { ANABELA MARTINS, }^{\mathrm{b}}
$$

${ }^{a}$ CIMO-ESA, Instituto Politécnico de Bragança, Campus de Santa Apolónia, Apartado 1172, 5301-855 Bragança, Portugal.

${ }^{\mathrm{b}}$ Escola Superior Agrária, Instituto Politécnico de Bragança, Campus de Santa Apolónia, Apartado 1172, 5301-855 Bragança, Portugal.

* Author to whom correspondence should be addressed (e-mail: iferreira@ipb.pt telephone +351-273-303219; fax +351-273-325405). 


\begin{abstract}
Ectomycorrhizal symbiosis between fungi mycelia and the roots of some plants could have important effects in the levels of antioxidants of both partners. In the present work, the effects of co-culture period in the antioxidant properties and antioxidants (phenolics, tocopherols and sugars) production during early steps of in vitro mycorrhization (Pinus pinaster-Pisolithus arhizus and Pinus pinaster-Paxillus involutus) were evaluated. The studied parameters were determined in each culture element (root, mycelium and medium) in order to understand the response of each partner to the symbiotic association. $P$. arhizus proved to be more compatible with $P$. pinaster than $P$. involutus, since the antioxidant activity in the latter species increased from 48 to $72 \mathrm{~h}$, while $P$. arhizus antioxidant properties decreased at the same period (indicative of less oxidative stress). Despite $P$. involutus proved to be less suitable to be included in forestation programs using mycorrhization processes, it revealed a higher potential for bioactive compounds production in the early steps of symbiosis. A maximal value of phenolics content was obtained after the first $6 \mathrm{~h}$.
\end{abstract}

Keywords: Ectomycorrhizal fungi; Pinus pinaster; symbiosis; co-culture period; antioxidants 


\section{Introduction}

Mycorrhiza absorbs mineral nutrients from soil and transports them to the root, while the plant provides photoassimilates, which are utilized by the fungus to grow and extend its mycelium to colonize the soil. Ectomycorrhizal (ECM) fungi are capable of infecting several arboreous species; thus, this symbiosis is widespread in both temperate and boreal forests and has been proposed to enhance significantly forest production. Ectomycorrhized plants survive better in adverse environmental conditions such as marginal soils, drought, pathogen attack, extreme $\mathrm{pH}$ and temperatures and other types of stress (Rodríguez-Tovar et al., 2005).

The basidiomycete Pisolithus arhizus is an almost ubiquitous ECM fungus, able to establish successful symbiosis with a wide range of plants (Marx, 1977), and it has been used as a model system for the analysis of ectomycorrhizal symbiotic interactions (Rodríguez-Tovar et al., 2005). Paxillus involutus is one of the most well-studied ECM fungi. The fungus is widespread in the Northern hemisphere and forms ECM with numerous coniferous and deciduous tree species (Wallander and Söderström, 1999). The unusually broad host range, relatively fast-growing mycelium, and rapid colonization of roots can explain why P. involutus is one of the most commonly used ECM fungi in laboratory experiments (Hedhi et al., 2008).

ECM symbiosis between the mycelia and the roots of some plants could have important effects in the levels of antioxidants of both partners: fungal mycelium and plant roots. In the early steps of mycorrhizal associations an oxidative burst might occur through the rapid production of high amounts of ROS (reactive oxygen species) in response to external stimuli (Lamb and Dixon, 1997; Baptista et al., 2007). Therefore, the production and/or activity of antioxidants, including enzymes (e.g. superoxide 
dismutase, catalase and peroxidase; Münzenberger et al., 1997; Baptista et al., 2007) or phenolic compounds, might increase in plant roots and/or mycelia (Münzenberger et al., 1995; Reis et al., 2011).

In previous works, mechanisms of symbiosis between ECM fungi (Pisolithus arhizus and Paxillus involutus) and a specific host plant (Pinus pinaster) were studied in vitro trough a long term mycorrhizal induction assay ( $48 \mathrm{~h}, 45$ days). $P$. arhizus seemed to be more compatible with $P$. pinaster than $P$. involutus, since the antioxidant activity in the latter species increased after a $48 \mathrm{~h}$ period, while $P$. arhizus remained unaffected (Reis et al., 2011; Reis et al., 2012). The present study aimed to evaluate the effects of coculture period in the antioxidant properties and antioxidants (phenolics, tocopherols and sugars) production during early steps of in vitro mycorrhization: 0,6 and $24 \mathrm{~h}$. An additional period of $72 \mathrm{~h}$ was also studied in order to understand if the chemical response followed up the same trend detected in the earlier periods. Furthermore, these parameters were determined in each culture element (root, mycelium and medium) in order to understand the response of each partner to the symbiotic association.

The obtained results will be discussed in two perspectives: interest in reforestation programs (Stenström et al., 1997) taking advantage on the compatibility between fungus and host plant; or interest in production of bioactive compounds (Ferreira et al., 2009) taking advantage on different compatibilities among plant and fungus that induce a higher production of antioxidant molecules.

\section{Materials and methods}

\subsection{In vitro production of mycelia and germination of Pinus pinaster seeds}


Mycelia of Paxillus involutus (Batsch) Fr. and Pisolithus arhizus (Scop.) Rauschert were isolated from sporocarps (Figure 1A,B; collected in Bragança, Portugal) on solid Melin-Norkans medium (MMN) pH $6.6\left(\mathrm{NaCl} 0.025 \mathrm{~g} / \mathrm{l} ;\left(\mathrm{NH}_{4}\right)_{2} \mathrm{HPO}_{4} 0.25 \mathrm{~g} / 1 ; \mathrm{KH}_{2} \mathrm{PO}_{4}\right.$ $0.50 \mathrm{~g} / \mathrm{l} ; \mathrm{FeCl}_{3} 0.0050 \mathrm{~g} / \mathrm{l} ; \mathrm{CaCl}_{2} 0.050 \mathrm{~g} / \mathrm{l} ; \mathrm{MgSO}_{4} .7 \mathrm{H}_{2} \mathrm{O} 0.15 \mathrm{~g} / \mathrm{l} ;$ thiamine $0.10 \mathrm{~g} / \mathrm{l}$ glucose $10 \mathrm{~g} / \mathrm{l}$; casamino acids $1.00 \mathrm{~g} / \mathrm{l}$, malt $5.00 \mathrm{~g} / \mathrm{l}$ and agar $20 \mathrm{~g} / \mathrm{l}$ in tap water) (Marx, 1969). The strains were maintained in Petri dishes (9 $\mathrm{cm}$ diameter) containing the same medium at $25^{\circ} \mathrm{C}$ in the dark and subcultured every 4 weeks (Figure 1C,D). Both mycelium and culture medium were weighted separately to obtain the fresh biomass (fw).

Pinus pinaster (Aiton) seeds (obtained in CENASEF, Centro Nacional das Sementes Florestais, Portugal) were sterilized with sodium hypochloride 5\% and two drops of tween ${ }^{\circledR} 80$ under agitation for 15 min (Harvengt, 2005). After washes with sterilized water, the seeds were poured in ethanol $80 \%$ for $15 \mathrm{~min}$, washed again with sterilized water, and finally poured in test tubes $(3 \mathrm{~cm}$ diameter) with agar:water $0.8 \%$. To induce germination, the tubes were kept in the dark at $25^{\circ} \mathrm{C}$ for $48 \mathrm{~h}$, and then exposed to light for day and night photoperiods $(16 \mathrm{~h} / 8 \mathrm{~h})$, respectively, in a culture chamber (Gro-Lux, Sylvania) with Daylight lamps (Phillips, Amsterdam, Netherlands) (Figure 1E,F).

\subsection{Induction of the mycorrhizal symbiosis}

Fungi mycelium was cultured in Petri dishes (12 cm diameter) with incomplete MMN (without malt and casamino acids) in slant and maintained for 20 days in the dark. Three Pinus pinaster seedlings were introduced in each Petri dish over the mycelium, and left in co-culture in the culture chamber and conditions mentioned above (Figure 1G,H). 
The part of the Petri dish where the plant roots were in contact with fungi was protected from light with aluminium paper, in order to mimetize the natural conditions of mycorrhizas development. After $0,6,24$ and $72 \mathrm{~h}$ of growth, mycelium and plant root were recovered from the medium. Mycelium, plant and culture medium were weighted separately to obtain the fresh biomass (fw), and then stored at $-40^{\circ} \mathrm{C}$ for further analyses. All the samples were lyophilised (FreeZone 4.5 model 7750031, Labconco, Kansas, USA) to obtain the dry biomass (dw) and further reduced to a fine dried powder (20 mesh).

\subsection{Standards and reagents}

Acetonitrile $99.9 \%, n$-hexane $95 \%$, ethyl acetate $99.8 \%$ and methanol were of HPLC grade from Fisher Scientific (Loures, Portugal). The standards sugars (D-fructose 98\%, D-glucose, D-sucrose 99.0\%, D-mannitol $98 \%$ and D-trehalose di-hydrate $99.5 \%$ ), tocopherols $(\alpha-, \quad \beta-, \quad \delta$-, and $\gamma$-isoforms), and trolox (6-hydroxy-2,5,7,8tetramethylchroman-2-carboxylic acid) were purchased from Sigma (St. Louis, MO, USA). Racemic tocol $50 \mathrm{mg} / \mathrm{mL}$, was purchased from Matreya (PA, USA). 2,2Diphenyl-1-picrylhydrazyl (DPPH) was obtained from Alfa Aesar (Ward Hill, MA, USA). All other chemicals and solvents were of analytical grade and purchased from common sources. Water was treated in a Milli-Q water purification system (TGI Pure Water Systems, USA).

\subsection{Evaluation of antioxidant activity}

\subsubsection{Preparation of the extracts}


Each sample ( $\sim 0.4 \mathrm{~g}$ for mycelia and plants; $4 \mathrm{~g}$ for culture media) was extracted by stirring with $30 \mathrm{ml}$ of methanol $\left(25^{\circ} \mathrm{C}\right.$ at $\left.150 \mathrm{rpm}\right)$ for $1 \mathrm{~h}$ and subsequently filtered through Whatman No. 4 paper. The residue was then extracted once more under the same conditions. The combined methanolic extracts were evaporated at $40^{\circ} \mathrm{C}$ (rotary evaporator Büchi R-210; Flawil, Switzerland) to dryness, and redissolved in methanol. In vitro assays already described by the authors (Barros et al., 2010) were used to evaluate the antioxidant activity of the samples.

\subsubsection{DPPH radical-scavenging activity}

This assay was performed in 96-well microtiter plates using an ELX800 Microplate Reader (Bio-Tek Instruments, Inc, Winooski, USA). The reaction mixture in each of the 96-wells of the plate consisted of one of the different concentrations of the extracts (30

$\mu \mathrm{l})$ and methanolic solution containing DPPH radicals $\left(6 \times 10^{-5} \mathrm{~mol} / \mathrm{l}, 270 \mu \mathrm{l}\right)$. The mixture was left to stand for $30 \mathrm{~min}$ in the dark. The reduction of the DPPH radical was determined by measuring the absorption at $515 \mathrm{~nm}$. The radical scavenging activity (RSA) was calculated as a percentage of DPPH discolouration using the equation: \% $R S A=\left[\left(A_{D P P H}-A_{S}\right) / A_{D P P H}\right] \times 100$, where $A_{S}$ is the absorbance of the solution when the sample extract has been added at a particular level, and $A_{D P P H}$ is the absorbance of the DPPH solution. The extract concentration providing $50 \%$ of radicals scavenging activity $\left(\mathrm{EC}_{50}\right)$ was calculated from the graph of RSA percentage against extract concentration. Trolox was used as standard.

\subsubsection{Reducing power}


This assay was also performed using microtiter plates and the Microplate Reader described above. Different concentrations of the extracts $(0.5 \mathrm{ml})$ were mixed with sodium phosphate buffer $(200 \mathrm{mmol} / \mathrm{l}, \mathrm{pH} 6.6,0.5 \mathrm{ml})$ and potassium ferricyanide $(1 \%$ $\mathrm{w} / \mathrm{v}, 0.5 \mathrm{ml}$ ). The mixture was incubated at $50^{\circ} \mathrm{C}$ for $20 \mathrm{~min}$, and trichloroacetic acid $(10 \% \mathrm{w} / \mathrm{v}, 0.5 \mathrm{ml})$ was added. The mixture $(0.8 \mathrm{ml})$ was poured into the wells of a $48-$ well microplate, as also deionised water $(0.8 \mathrm{ml})$ and ferric chloride $(0.1 \% \mathrm{w} / \mathrm{v}, 0.16$ $\mathrm{ml}$ ), and the absorbance was measured at $690 \mathrm{~nm}$. The extract concentration providing 0.5 of absorbance $\left(\mathrm{EC}_{50}\right)$ was calculated from the graph of absorbance at $690 \mathrm{~nm}$ against extract concentration. Trolox was used as standard.

\subsubsection{Inhibition of $\beta$-carotene bleaching}

A solution of $\beta$-carotene was prepared by dissolving $\beta$-carotene $(2 \mathrm{mg})$ in chloroform $(10 \mathrm{ml})$. Two millilitres of this solution were pipetted into a round-bottom flask. The chloroform was removed at $40^{\circ} \mathrm{C}$ under vacuum and linoleic acid (40 mg), Tween 80 emulsifier (400 mg), and distilled water $(100 \mathrm{ml})$ were added to the flask with vigorous shaking. Aliquots $(4.8 \mathrm{ml})$ of this emulsion were transferred into test tubes containing different concentrations of the extracts $(0.2 \mathrm{ml})$. The tubes were shaken and incubated at $50^{\circ} \mathrm{C}$ in a water bath. As soon as the emulsion was added to each tube, the zero time absorbance was measured at $470 \mathrm{~nm}$ (Analytikjena 200 spectrophotometer, Jena, Germany). $\beta$-Carotene bleaching inhibition was calculated using the following equation: $(\beta$-carotene content after $2 \mathrm{~h}$ of assay/initial $\beta$-carotene content $) \times 100$. The extract concentration providing $50 \%$ antioxidant activity $\left(\mathrm{EC}_{50}\right)$ was calculated by interpolation 
from the graph of $\beta$-carotene bleaching inhibition percentage against extract concentration. Trolox was used as standard.

\subsubsection{Inhibition of lipid peroxidation using thiobarbituric acid reactive substances} (TBARS)

Porcine (Sus scrofa) brains were obtained from official slaughtering animals, dissected, and homogenized with a Polytron in ice cold Tris- $\mathrm{HCl}$ buffer $(20 \mathrm{mM}, \mathrm{pH} 7.4)$ to produce a 1:2 w/v brain tissue homogenate which was centrifuged at $3000 \mathrm{~g}$ for10 min. An aliquot $(0.1 \mathrm{ml})$ of the supernatant was incubated with the different concentrations of the samples solutions $(0.2 \mathrm{ml})$ in the presence of $\mathrm{FeSO}_{4}(10 \mathrm{mM} ; 0.1 \mathrm{ml})$ and ascorbic acid $(0.1 \mathrm{mM} ; 0.1 \mathrm{ml})$ at $37{ }^{\circ} \mathrm{C}$ for $1 \mathrm{~h}$. The reaction was stopped by the addition of trichloro acetic acid $(28 \% \mathrm{w} / \mathrm{v}, 0.5 \mathrm{ml})$, followed by thiobarbituric acid (TBA, $2 \%$, w/v, $0.38 \mathrm{ml}$ ), and the mixture was then heated at $80{ }^{\circ} \mathrm{C}$ for $20 \mathrm{~min}$. After centrifugation at $3000 \mathrm{~g}$ for $10 \mathrm{~min}$ to remove the precipitated protein, the colour intensity of the malondialdehyde (MDA)-TBA complex in the supernatant was measured by its absorbance at $532 \mathrm{~nm}$. The inhibition ratio (\%) was calculated using the following formula: Inhibition ratio $(\%)=[(\mathrm{A}-\mathrm{B}) / \mathrm{A}] \times 100 \%$, where $\mathrm{A}$ and $\mathrm{B}$ were the absorbance of the control and the sample solution, respectively.

\subsection{Determination of antioxidant compounds}

\subsubsection{Total phenolics}

An aliquot of the extract solution $(0.5 \mathrm{ml})$ was mixed with Folin-Ciocalteu (FC) reagent $(2.5 \mathrm{ml}$, previously diluted with water $1: 10 \mathrm{v} / \mathrm{v})$ and sodium carbonate $(75 \mathrm{~g} / 1,2 \mathrm{ml})$. The tubes were vortexed for $15 \mathrm{~s}$ and allowed to stand for $30 \mathrm{~min}$ at $40^{\circ} \mathrm{C}$ for colour 
development. Absorbance was then measured at $765 \mathrm{~nm}$. Gallic acid was used to calculate the standard curve $(0.0094-0.15 \mathrm{mg} / \mathrm{ml})$, and the results were expressed as mg of gallic acid equivalents (GAEs) per g of extract.

\subsubsection{Tocopherols}

Tocopherols content was determined following a procedure previously optimized and described by Barros et al. (2008), using tocol as internal standard. The HPLC equipment consisted of an integrated system with a Smartline 1000 pump (Knauer, Berlin, Germany), a Smartline manager 5000 degasser, an AS-2057 auto-sampler (Jasco, Easton, MD) and a FP-2020 fluorescence detector (Jasco, Easton, MD) programmed for excitation at $290 \mathrm{~nm}$ and emission at $330 \mathrm{~nm}$.. Data were analysed using Clarity 2.4 Software (DataApex). The column used was a normal-phase $250 \mathrm{~mm} \times 4.6 \mathrm{~mm}$ i.d., 5 $\mu \mathrm{m}$, Polyamide II, with a $10 \mathrm{~mm} \times 4 \mathrm{~mm}$ i.d. guard column of the same material (YMC Waters, Dinslaken, Germany), operating at $30^{\circ} \mathrm{C}$. The mobile phase used was a mixture of $n$-hexane and ethyl acetate $(70: 30, \mathrm{v} / \mathrm{v})$ at a flow rate of $1 \mathrm{ml} / \mathrm{min}$. Tocopherols identification was made by comparing the relative retention times of sample peaks with standards. Quantification was based on the fluorescence signal response, using the internal standard method, and the results were expressed in mg per $\mathrm{g}$ of dry weight $(d w)$.

\subsubsection{Soluble sugars}

Sugars content was determined following a procedure previously optimized and described by Heleno et al. (2009), using melezitose as internal standard. The HPLC 
system described above was connected to a Smartline 2300 refraction index (RI) detector (Knauer). Data were analysed using Clarity 2.4 Software (DataApex). The chromatographic separation was achieved with a Eurospher 100-5 $\mathrm{NH}_{2}$ column $(4.6 \times$ $250 \mathrm{~mm}$, $5 \mathrm{~mm}$, Knauer) operating at $30^{\circ} \mathrm{C}$. The mobile phase was acetonitrile/deionized water, $70: 30(\mathrm{v} / \mathrm{v})$ at a flow rate of $1 \mathrm{ml} / \mathrm{min}$. Sugars identification was made by comparing the relative retention times of sample peaks with standards. Quantification was made by the internal standard method and the results were expressed in $g$ per $100 \mathrm{~g}$ of dry weight $(\mathrm{dw})$.

\subsection{Statistical analysis}

An analysis of variance (ANOVA) with Type III sums of squares was performed using the GLM (General Linear Model) procedure of the SPSS software, version 18.0 (SPSS, Inc.). All dependent variables were analyzed using a 2-way ANOVA, being the main factors the "culture element" (Pinus pinaster root, mycelium and culture medium) and the "co-culture period" $(0,6,24$ and 72 h). Since a statistical significant interaction effect ("culture element×co-culture period") was found in all tests, the two factors were evaluated simultaneously by plotting the estimated marginal means for all levels of each factor. In addition, a linear discriminant analysis (LDA) was used as a technique to classify the three culture elements as well as the four co-culture periods according to their antioxidant activity results, and their phenolics, sugars and tocopherols contents. A stepwise technique, using the Wilks' $\lambda$ method with the usual probabilities of $F$ (3.84 to enter and 2.71 to remove), was applied for variable selection. This procedure uses a combination of forward selection and backward elimination procedures, where before selecting a new variable to be included, it is verified whether all variables previously 
selected remain significant (Rencher, 1995; Maroco, 2003; López et al., 2008). With this approach, it is possible to identify the significant variables among the antioxidant activity, and phenolics, sugars and tocopherols profiles obtained for each sample. To verify which canonical discriminant functions were significant, the Wilks' $\lambda$ test was applied. To avoid overoptimistic data modulation, a leaving-one-out cross-validation procedure was carried out to assess the model performance. The LDA statistical analysis and the other statistical tests were performed at a 5\% significance level using the SPSS software mentioned above.

\section{Results and discussion}

In a previous work of our research group, symbiotic associations were studied after different co-culture periods, 45 days and 48 h (Reis et al., 2012), revealing different responses depending on the used fungi. P. arhizus seemed to be more compatible with $P$. pinaster than $P$. involutus, since the antioxidant activity in the latter species increased after a 48 h period, while $P$. arhizus remained unaffected (Reis et al., 2011; Reis et al., 2012). Nevertheless, the mechanisms of antioxidants production are still unknown and, therefore, the present study was conducted during early steps of in vitro mycorrhization: 0,6 and $24 \mathrm{~h}$. If the antioxidant activity increases in the earlier stages, this might indicate a response mechanism resulting from higher oxidative stress levels while the host plant does not recognize the fungus as a friendly species. An additional period of $72 \mathrm{~h}$ was also studied in order to understand if the chemical response followed up the same trend detected in the earlier periods.

The different compatibilities among plant and fungus might be used with beneficial purposes. A good compatibility between them will mean a very low oxidative stress, 
and therefore a low production of secondary metabolites. In this case, the fungi might be a good choice to join with the plant for reforestation programs. On the other hand, if the compatibility is low, the oxidative stress will peak at some stage, and the production of metabolites will be very high, making the association interesting to purify the antioxidants produced; in this case, it would be important to define the most suitable time to stop the co-culture in order to maximize the bioactive compound yield. Otherwise, if the fungus does not cause a significant reaction by the host, this could be interpreted as a compatibility indicator with interest in reforestation programs.

Antioxidant activity $\mathrm{EC}_{50}$ values and phenolic (Table 1), tocopherols (Table 2) and sugars (Table 3) contents are reported as mean value of each culture element (CE) over the different co-culture periods (CP) as well as mean value of all elements within each co-culture period. The presentation of the results in this form is more adequate to evaluate the effects of both factors (CE and $\mathrm{CP}$ ) independently of each other, thus avoiding interaction based outcomes. The results show that the interaction $\mathrm{CP} \times \mathrm{CE}$ was a significant $(p<0.001)$ source of variation for all the evaluated parameters. Hence, although the least squares means are presented for the main effects, no multiple comparisons were performed. Furthermore, both main factors (CP and $\mathrm{CE}$ ) showed a significant effect $(p<0.001)$. However, from the analysis of the plots of the estimated margins means (data shown only in specific cases), for each variable, some general conclusions can be acquired.

For instance, in $P$. arhizus- $P$. pinaster co-culture, the antioxidant activity remained nearly constant in $P$. pinaster root, while $P$. arhizus mycelium showed a significant decrease (increase of $\mathrm{EC}_{50}$ values) for the $72 \mathrm{~h}$ period, after keeping similar values in the first $24 \mathrm{~h}$. Regarding culture medium, the results were analogous to those obtained 
for the mycelium, except for $\beta$-carotene bleaching assay. This outcome might indicate that after an initial physiological adaptation period, reflected by slight changes in the antioxidant activity, at $72 \mathrm{~h}$ the plant had already recognized the fungus as nonpathogenic. As it is only evident in plots of the estimated margins means (data not shown) and not in table 1, it should be clarified that these differences were mainly related with the culture medium.

For $P$. involutus-P. pinaster co-culture, the $\mathrm{EC}_{50}$ values obtained for $\mathrm{DPPH}$ scavenging activity and reducing power assays were lower (mainly in the culture medium) than the obtained with the other fungi (Table 1), which is in agreement with the reported by Reis et al. (2011, 2012) and with its higher phenolic content (Table 1). Despite some similarities in the antioxidant activities obtained in each mycorrhization, there are some particular results which may define some compatibility differentiation. For instance, while the $\mathrm{EC}_{50}$ values tended to increase from 24 to $72 \mathrm{~h}$ in $P$. arhizus (except for $\beta$ carotene bleaching assay), the same values were almost unaffected in $P$. involutus, for the same period (except for TBARS assay) (Table 1). Nonetheless, in both cases, the antioxidant activity is maintained close to constant in each mycelium and root, varying significantly in the culture medium. Even so, while the phenolic contents were maximal at $0 \mathrm{~h}$ in $P$. arhizus- $P$. pinaster co-culture (148 $\mathrm{mg} \mathrm{GAE} / \mathrm{g})$, their highest value was obtained at $6 \mathrm{~h}$ for $P$. involutus- $P$. pinaster (154 mg GAE/g) (Table 1). This might indicate that the antioxidant activity is supported not only by phenolic compounds, since mycelium and root maintained their antioxidant potential despite the variation in phenolics contents. Furthermore, the increase in the antioxidant activity of the culture medium was not convoyed by a rise of the phenolics content. 
Regarding tocopherols, $\alpha$ - and $\delta$-tocopherol were higher in $P$. pinaster root, while $\gamma$ tocopherol was the prevalent vitamer in the mycelia for both co-cultures, but presenting higher values in P. arhizus (Figure 2A, Table 2). An interesting finding is related with the high variation along $\mathrm{CP}$ of $\alpha$ - and $\delta$-tocopherol in the $P$. arhizus- $P$. pinaster coculture (Table 2), while in the $P$. involutus- $P$. pinaster co-culture, only $\delta$-tocopherol showed a significant decrease along $\mathrm{CP}$, indicating that the metabolic dynamics of vitamin $\mathrm{E}$ might be affected by the symbiont species. In general, total tocopherols did not vary in the culture medium for both mycorrhizations but although $P$. pinaster root was the element with higher tocopherols content in the $P$. involutus- $P$. pinaster coculture, the mycelium was the element with higher content of this vitamin in the $P$. arhizus-P. pinaster co-culture (Table 2).

Considering sugars contents, fructose and sucrose were only detected in $P$. pinaster root in both co-cultures, despite the content in both sugars were higher in the $P$. pinaster- $P$. arhizus co-culture (Table 3). However, while fructose increased and sucrose was maintained constant in the $P$. arhizus- $P$. pinaster co-culture along $\mathrm{CP}$, both sugars decreased in the $P$. involutus- $P$. pinaster co-culture. Mannitol was only found in $P$. involutus mycelium while trehalose was found in both mycelia (Figure 2B; Table 3). In the $P$. involutus- $P$. pinaster co-culture, mannitol tended to decrease in the mycelium and to remain unaffected in the root, while trehalose augmented in the root and lowered in the mycelium. Glucose showed an interesting behavior along time, since their variation denoted an apparent complementarity among $P$. pinaster root and $P$. arhizus mycelium, a tendency that was also reflected in the total sugars content (Figure 3A); in the $P$. pinaster-P. involutus co-culture, glucose varied only in the root, in which tended to 
decrease. The $P$. pinaster- $P$. arhizus co-culture elements presented higher sugars values, mainly based on the results obtained for fructose and trehalose (Table 3).

In general, there was a dual constancy among the assayed parameters. The antioxidant activity remained quite similar in $P$. pinaster root and in each one of the mycelia used in both co-cultures, while tocopherols (except $\gamma$-tocopherol) contents showed high similarities among culture medium and mycelia. This tendency could not be observed regarding sugars contents, an observation that might indicate that the differences in the chemical responses that characterize each mycorrhization might be related more directly with sugar (primary metabolites) exchanges.

In order to better understand the time induced differences, as well as the differences among each one of the co-culture elements, a linear discriminant analysis (LDA) was applied. The differences induced by the co-culture period for the mycorrhization with $P$. pinaster are well observed in this analysis, in which four clusters (corresponding to the four assayed periods) were clearly individualized (Figure 4A). In this case, all the assayed parameters (antioxidant activity assays $\mathrm{EC}_{50}$ values, phenolics, tocopherols and sugars contents) were used, resulting in a discriminant model with three significant ( $p<$ 0.001 for the Wilks' $\lambda$ test) discriminant functions. These three functions explained $100.0 \%$ of the variance of the experimental data (the first explained $93.8 \%$, the second $4.3 \%$ and the third $1.9 \%$ ) (Figure $4 \mathbf{A}$ ). The model showed a very satisfactory classification performance allowing to correctly classifying $100.0 \%$ of the samples for the original groups and $99.1 \%$ for the cross-validation procedure.

A similar result was also obtained for $P$. involutus- $P$. pinaster co-culture. The applied LDA also allowed the formation of four individual clusters, after the definition of three significant $(p<0.001$ for the Wilks' $\lambda$ test $)$ discriminant functions, which explained 
$100.0 \%$ of the variance of the experimental data (the first explained $85.6 \%$, the second $12 \%$ and the third 2.4\%) (Figure 4B). The model showed a very satisfactory classification performance allowing to correctly classifying $98.1 \%$ of the samples for the original groups and $96.3 \%$ for the cross-validation procedure.

Regarding the co-culture elements, there seemed to be an apparent similarity along time, especially in the antioxidant properties, in both assayed co-cultures, indicating that the symbiosis did not affect the antioxidant properties of the studied species. However, the LDA results indicated that the slight differences found among those two elements are sufficient to discriminate them in two separate groups, either for P. arhizus (Figure 5A), as for $P$. involutus. In both cases, the LDA defined two significant ( $p<0.001$ for the Wilks' $\lambda$ test) functions which explained $100.0 \%$ of the variance of the experimental data. The model showed a very satisfactory classification performance allowing to correctly classifying $90.7 \%$ of the samples for the original groups as well as of the cross-validation procedure for $P$. involutus. A similar result was obtained when the analysis was performed using tocopherols $(91.7 \%$ of the samples for the original groups as well as of the cross-validation procedure were correctly classified) and sugars (Figure 5B) $(100.0 \%$ of the samples for the original groups as well as of the crossvalidation procedure were correctly classified). For $P$. arhizus $100.0 \%$ of the samples for the original groups as well as of the cross-validation procedure were correctly classified using antioxidant activity $\mathrm{EC}_{50}$ values, tocopherols or sugars.

Overall, this study demonstrated the hypothesis suggested by Reis et al. $(2011,2012)$ which stated $P$. arhizus as more compatible with $P$. pinaster than $P$. involutus, since the antioxidant activity in the latter species increased from 48 to $72 \mathrm{~h}$, while P. arhizus 
antioxidant properties decreased at the same period (indicative of less oxidative stress). Despite $P$. involutus proved to be less suitable to be included in forestation programs using mycorrhization processes, it revealed a higher potential of bioactive compounds production in the early steps of symbiosis. In fact, a maximal value of phenolics content was obtained after the first $6 \mathrm{~h}$ (Figure 3B) and, therefore, considering bioactive compounds production purposes, the co-culture should be stopped at that time.

\section{Acknowledgements}

The authors are grateful to Fundação para a Ciência e a Tecnologia (FCT, Portugal) and COMPETE/QREN/EU for financial support to this work (research project PTDC/AGRALI/110062/2009) and to CIMO (strategic project PEst-OE/AGR/UI0690/2011). L. Barros and J.C.M. Barreira thank to FCT, POPH-QREN and FSE for their grants (SFRH/BPD/4609/2008 and SFRH/BPD/72802/2010, respectively).

\section{References}

Baptista, P., Martins, A., Pais, M.S., Tavares, R.M., Lino-Neto, T. 2007. Involvement of reactive oxygen species during early stages of ectomycorrhiza establishment between Castanea sativa and Pisolithus tinctorius. Mycorrhiza 17, 185-193.

Barros, L., Correia, D.M., Ferreira, I.C.F.R., Baptista, P., Santos-Buelga, C. 2008. Optimization of the determination of tocopherols in Agaricus sp. edible mushrooms by a normal phase liquid chromatographic method. Food Chem. 4, 1046-1050.

Barros, L., Oliveira, S., Carvalho, A.M., Ferreira, I.C.F.R. 2010. In vitro antioxidant properties and characterization in nutrients and phytochemicals of six medicinal plants from the Portuguese folk medicine. Ind. Crops Prod. 32, 572-579. 
Ferreira, I.C.F.R., Barros, L., Abreu, R.M.V. 2009. Antioxidants in wild mushrooms. Curr. Med. Chem. 16, 1543-1560.

Harvengt, L. 2005. Somatic embryogenesis in maritime pine (Pinus pinaster Ait). Foresty Sci. 77, 107-119.

Hedhi, J., Samson, P., Erland, S., Tunlid, A. 2008. Multiple gene genealogies and species recognition in the ectomycorrhizal fungus Paxillus involutus. Mycol. Res. $112,965-975$.

Heleno, S.A., Barros, L., Sousa, M.J., Martins, A., Ferreira, I.C.F.R. 2009. Study and characterization of selected nutrients in wild mushrooms from Portugal by gas chromatography and high performance liquid chromatography. Microchem. J. 93, 195-199.

Lamb, C, Dixon, R.A. 1997. The oxidative burst in plant disease resistance. Annu. Rev. Plant Physiol. Plant Mol. Biol. 48, 251-275.

López, A., García, P., Garrido, A. 2008. Multivariate characterization of table olives according to their mineral nutrient composition, Food Chem. 106, 369-378.

Maroco, J. 2003. Análise Estatística, com utilização do SPSS, Edições Sílabo, Lisboa, Portugal.

Marx, D.H. 1969. The influence of ectotrophic fungi on the resistance of pine root to pathogenic infections. I. Antagonism of mycorrhizal fungi to root pathogenic fungi and soil bacteria. Phytopathol. 59, 153-163.

Marx, D.H. 1977. Tree host range and world distribution of the ectomycorrhizal fungus Pisolithus tinctorius. Can. J. Microbiol. 23, 217- 223.

Münzenberger, B., Kottke, I., Oberwinkler, F. 1995. Reduction of phenolics in mycorrhizas of Larix decidua Mill. Tree Physiol. 15, 191-196. 
Münzenberger, B., Otter, T., Wüstrich, D., Polle, A. 1997. Peroxidase and laccase activities in mycorrhizal and non-mycorrhizal fine roots of Norway spruce (Picea abies) and larch (Larix decidua). Can. J. Bot. 78, 932-938.

Reis, F.S., Ferreira, I.C.F.R., Barros, L., Santos-Buelga, C., Martins, A. 2011. Mycorrhizal induction of phenolic compounds and antioxidant properties of fungi and seedlings during the early steps of symbiosis. Chemoecology 21, 151-159.

Reis, F.S., Ferreira, I.C.F.R., Martins, A. 2012. Effect of the mycorrhizal symbiosis time in the antioxidant activity of fungi and Pinus pinaster roots, stems and leaves. Ind. Crops Prod. 35, 211-216.

Rencher, A.C. 1995. Methods of Multivariate Analysis, John Willey, New York.

Rodríguez-Tovara, A.V., Ruiz-Medrano, R., Herrera-Martíneza, A., Barrera-Figueroa, B.E., Hidalgo-Lara, M.E., Reyes-Márquez, B.E., Cabrera-Ponce, J.L., Valdés, M., Xoconostle-Cázares, B. 2005. Stable genetic transformation of the ectomycorrhizal fungus Pisolithus tinctorius. J. Microbiol. Method. 63, 45-54.

Stenström, E., Damm, E., Unestam, T. 1997. Le rôle des mycorrhizes dans la protection des arbres forestiers contre les agents pathogènes du sol. Rev. For Fr. 121- 128.

Wallander, H., Söderström, B. 1999. Paxillus. In: Cairney, J.W.G., Chambers, S.M. (eds). Ectomycorrhizal Fungi: key genera in profile. Springer-Verlag, Berlin, pp. 231252. 
Table 1. Antioxidant activity $\mathrm{EC}_{50}$ values $(\mathrm{mg} / \mathrm{ml})$ and phenolic content $(\mathrm{mg} \mathrm{GAE} / \mathrm{g}$ extract) obtained for the culture elements $(\mathrm{CE})$. The results are presented as mean $\pm \mathrm{SD}^{\mathrm{a}}$ $(n=27$, for each co-culture period (CP); $n=36$ for each culture element).

\begin{tabular}{|c|c|c|c|c|c|c|}
\hline & & $\begin{array}{c}\text { DPPH } \\
\text { scavenging } \\
\text { activity }\end{array}$ & $\begin{array}{l}\text { Reducing } \\
\text { power }\end{array}$ & $\begin{array}{c}\beta \text {-Carotene } \\
\text { bleaching } \\
\text { inhibition }\end{array}$ & $\begin{array}{l}\text { TBARS } \\
\text { assay }\end{array}$ & Phenolics \\
\hline \multicolumn{7}{|c|}{ Pisolithus arhizus } \\
\hline \multirow{5}{*}{$\mathrm{CP}$} & $0 \mathrm{~h}$ & $27 \pm 38$ & $8 \pm 11$ & $1 \pm 1$ & $0.1 \pm 0.2$ & $148 \pm 107$ \\
\hline & $6 \mathrm{~h}$ & $37 \pm 52$ & $10 \pm 14$ & $3 \pm 4$ & $1 \pm 1$ & $107 \pm 90$ \\
\hline & $24 \mathrm{~h}$ & $16 \pm 23$ & $5 \pm 7$ & $11 \pm 15$ & $2 \pm 3$ & $82 \pm 60$ \\
\hline & $72 \mathrm{~h}$ & $29 \pm 41$ & $35 \pm 50$ & $1.0 \pm 0.5$ & $3 \pm 4$ & $99 \pm 77$ \\
\hline & $p$-value & $<0.001$ & $<0.001$ & $<0.001$ & $<0.001$ & $<0.001$ \\
\hline \multirow{4}{*}{$\mathrm{CE}$} & Root & $0.2 \pm 0.1$ & $0.13 \pm 0.03$ & $0.7 \pm 0.3$ & $0.1 \pm 0.1$ & $199 \pm 42$ \\
\hline & Mycelium & $1.0 \pm 0.3$ & $0.8 \pm 0.1$ & $0.5 \pm 0.2$ & $0.06 \pm 0.04$ & $125 \pm 38$ \\
\hline & Medium & $80 \pm 22$ & $43 \pm 37$ & $11 \pm 12$ & $4 \pm 4$ & $3 \pm 1$ \\
\hline & $p$-value & $<0.001$ & $<0.001$ & $<0.001$ & $<0.001$ & $<0.001$ \\
\hline $\mathrm{CP} \times \mathrm{CE}$ & $p$-value & $<0.001$ & $<0.001$ & $<0.001$ & $<0.001$ & $<0.001$ \\
\hline \multicolumn{7}{|c|}{ Paxillus involutus } \\
\hline \multirow{5}{*}{$\mathrm{CP}$} & $0 \mathrm{~h}$ & $3 \pm 4$ & $3 \pm 4$ & $2 \pm 3$ & $3 \pm 5$ & $146 \pm 106$ \\
\hline & $6 \mathrm{~h}$ & $5 \pm 6$ & $7 \pm 10$ & $3 \pm 3$ & $4 \pm 6$ & $154 \pm 160$ \\
\hline & $24 \mathrm{~h}$ & $3 \pm 3$ & $3 \pm 4$ & $2 \pm 3$ & $4 \pm 5$ & $126 \pm 122$ \\
\hline & $72 \mathrm{~h}$ & $3 \pm 3$ & $2 \pm 3$ & $3 \pm 3$ & $8 \pm 11$ & $95 \pm 81$ \\
\hline & $p$-value & $<0.001$ & $<0.001$ & $<0.001$ & $<0.001$ & $<0.001$ \\
\hline \multirow{4}{*}{$\mathrm{CE}$} & Root & $0.6 \pm 0.3$ & $0.3 \pm 0.2$ & $0.8 \pm 0.5$ & $0.01 \pm 0.01$ & $125 \pm 74$ \\
\hline & Mycelium & $0.4 \pm 0.2$ & $0.18 \pm 0.05$ & $0.4 \pm 0.3$ & $0.1 \pm 0.1$ & $261 \pm 78$ \\
\hline & Medium & $9 \pm 3$ & $11 \pm 5$ & $7 \pm 1$ & $14 \pm 6$ & $6 \pm 1$ \\
\hline & $p$-value & $<0.001$ & $<0.001$ & $<0.001$ & $<0.001$ & $<0.001$ \\
\hline$\overline{\mathrm{CP} \times \mathrm{CE}}$ & $p$-value & $<0.001$ & $<0.001$ & $<0.001$ & $<0.001$ & $<0.001$ \\
\hline
\end{tabular}


${ }^{a}$ Results are reported as mean value of each culture element (CE) over the different coculture periods (CP) as well as mean value of all elements within each co-culture period. 
Table 2. Tocopherols content $(\mathrm{mg} / 100 \mathrm{~g} \mathrm{dw})$ in the culture elements (CE). The results are presented as mean $\pm \mathrm{SD}^{\mathrm{a}}(\mathrm{n}=27$, for each co-culture period $(\mathrm{CP}) ; \mathrm{n}=36$ for each culture element).

\begin{tabular}{|c|c|c|c|c|c|c|}
\hline & & $\alpha$-Tocopherol & $\beta$-Tocopherol & $\gamma$-Tocopherol & $\delta$-Tocopherol & Total tocopherols \\
\hline \multicolumn{7}{|c|}{ Pisolithus arhizus } \\
\hline \multirow{5}{*}{$\mathrm{CP}$} & $0 \mathrm{~h}$ & $1 \pm 2$ & $0.1 \pm 0.1$ & $15 \pm 20$ & $9 \pm 12$ & $25 \pm 18$ \\
\hline & $6 \mathrm{~h}$ & $1 \pm 1$ & $0.06 \pm 0.04$ & $10 \pm 13$ & $1 \pm 1$ & $11 \pm 12$ \\
\hline & $24 \mathrm{~h}$ & $1 \pm 1$ & $0.05 \pm 0.03$ & $12 \pm 17$ & $1 \pm 2$ & $14 \pm 16$ \\
\hline & $72 \mathrm{~h}$ & $9 \pm 12$ & $0.4 \pm 0.5$ & $15 \pm 21$ & $3 \pm 4$ & $27 \pm 19$ \\
\hline & $p$-value & $<0.001$ & $<0.001$ & $<0.001$ & $<0.001$ & 0.001 \\
\hline \multirow{4}{*}{$\mathrm{CE}$} & Root & $8 \pm 10$ & $0.3 \pm 0.5$ & $0.3 \pm 0.2$ & $10 \pm 10$ & $19 \pm 15$ \\
\hline & Mycelium & $0.2 \pm 0.2$ & $0.1 \pm 0.1$ & $38 \pm 7$ & $0.05 \pm 0.05$ & $38 \pm 7$ \\
\hline & Medium & $0.03 \pm 0.04$ & $0.06 \pm 0.02$ & $0.5 \pm 0.3$ & $0.2 \pm 0.3$ & $0.7 \pm 0.5$ \\
\hline & $p$-value & $<0.001$ & $<0.001$ & $<0.001$ & $<0.001$ & $<0.001$ \\
\hline $\mathrm{CP} \times \mathrm{CE}$ & $p$-value & $<0.001$ & $<0.001$ & $<0.001$ & $<0.001$ & $<0.001$ \\
\hline \multicolumn{7}{|c|}{ Paxillus involutus } \\
\hline \multirow{5}{*}{$\mathrm{CP}$} & $0 \mathrm{~h}$ & $1 \pm 2$ & $0.02 \pm 0.03$ & $0.5 \pm 0.1$ & $9 \pm 12$ & $11 \pm 15$ \\
\hline & $6 \mathrm{~h}$ & $1 \pm 1$ & nd & $0.6 \pm 0.5$ & $2 \pm 2$ & $3 \pm 3$ \\
\hline & $24 \mathrm{~h}$ & $1 \pm 1$ & $0.01 \pm 0.01$ & $0.9 \pm 0.4$ & $1 \pm 2$ & $3 \pm 2$ \\
\hline & $72 \mathrm{~h}$ & $1 \pm 1$ & $0.01 \pm 0.01$ & $1 \pm 1$ & $1 \pm 2$ & $3 \pm 2$ \\
\hline & $p$-value & $<0.001$ & $<0.001$ & $<0.001$ & $<0.001$ & 0.001 \\
\hline \multirow{4}{*}{$\mathrm{CE}$} & Root & $2 \pm 1$ & $0.01 \pm 0.02$ & $0.5 \pm 0.1$ & $10 \pm 10$ & $12 \pm 11$ \\
\hline & Mycelium & $0.004 \pm 0.001$ & $0.01 \pm 0.01$ & $1.3 \pm 0.5$ & $0.03 \pm 0.02$ & $1.4 \pm 0.5$ \\
\hline & Medium & nd & nd & $0.3 \pm 0.3$ & nd & $0.3 \pm 0.3$ \\
\hline & $p$-value & $<0.001$ & $<0.001$ & $<0.001$ & $<0.001$ & $<0.001$ \\
\hline $\mathrm{CP} \times \mathrm{CE}$ & $p$-value & $<0.001$ & $<0.001$ & $<0.001$ & $<0.001$ & $<0.001$ \\
\hline
\end{tabular}


${ }^{a}$ Results are reported as mean value of each culture element (CE) over the different coculture periods (CP) as well as mean value of all elements within each co-culture period. 
Table 3. Sugars content $(\mathrm{g} / 100 \mathrm{~g} \mathrm{dw})$ in the culture elements $(\mathrm{CE})$. The results are presented as mean $\pm \mathrm{SD}^{\mathrm{a}}$ ( $\mathrm{n}=27$, for each co-culture period $(\mathrm{CP}) ; \mathrm{n}=36$ for each culture element).

\begin{tabular}{|c|c|c|c|c|c|c|c|}
\hline & & Fructose & Glucose & Mannitol & Sucrose & Trehalose & Total sugars \\
\hline & & & Pisolith & us arhizus & & & \\
\hline & $0 \mathrm{~h}$ & $1 \pm 2$ & $10 \pm 8$ & $0.3 \pm 0.4$ & $1 \pm 1$ & $2 \pm 2$ & $14 \pm 6$ \\
\hline & $6 \mathrm{~h}$ & $1 \pm 2$ & $11 \pm 10$ & $0.2 \pm 0.2$ & $1 \pm 1$ & $1 \pm 2$ & $14 \pm 8$ \\
\hline $\mathrm{CP}$ & $24 \mathrm{~h}$ & $2 \pm 2$ & $11 \pm 11$ & $0.3 \pm 0.4$ & $1 \pm 1$ & $1 \pm 1$ & $15 \pm 9$ \\
\hline & $72 \mathrm{~h}$ & $3 \pm 4$ & $11 \pm 10$ & $0.1 \pm 0.2$ & $1 \pm 1$ & $1 \pm 2$ & $16 \pm 8$ \\
\hline & $p$-value & $<0.001$ & $<0.001$ & $<0.001$ & $<0.001$ & $<0.001$ & $<0.001$ \\
\hline & Root & $5 \pm 2$ & $5 \pm 1$ & $0.6 \pm 0.2$ & $1.9 \pm 0.3$ & nd & $13 \pm 3$ \\
\hline CГ & Mycelium & nd & $2.7 \pm 0.5$ & nd & nd & $4 \pm 1$ & $7 \pm 1$ \\
\hline & Medium & nd & $24 \pm 2$ & nd & nd & nd & $24 \pm 2$ \\
\hline & $p$-value & $<0.001$ & $<0.001$ & $<0.001$ & $<0.001$ & $<0.001$ & $<0.001$ \\
\hline $\mathrm{CP} \times \mathrm{CE}$ & $p$-value & $<0.011$ & $<0.001$ & $<0.001$ & $<0.001$ & $<0.001$ & $<0.001$ \\
\hline & & & Paxillu & involutus & & & \\
\hline & $0 \mathrm{~h}$ & $1 \pm 2$ & $11 \pm 11$ & $0.5 \pm 0.4$ & $1 \pm 1$ & $0.2 \pm 0.3$ & $14 \pm 10$ \\
\hline & $6 \mathrm{~h}$ & $0.03 \pm 0.05$ & $9 \pm 12$ & $0.3 \pm 0.4$ & $0.1 \pm 0.1$ & $0.3 \pm 0.4$ & $10 \pm 12$ \\
\hline $\mathrm{CP}$ & $24 \mathrm{~h}$ & $0.04 \pm 0.06$ & $10 \pm 13$ & $0.3 \pm 0.4$ & $0.1 \pm 0.1$ & $0.1 \pm 0.1$ & $10 \pm 13$ \\
\hline & $72 \mathrm{~h}$ & $0.05 \pm 0.07$ & $9 \pm 13$ & $0.3 \pm 0.4$ & $0.2 \pm 0.3$ & $0.1 \pm 0.1$ & $10 \pm 12$ \\
\hline & $p$-value & $<0.001$ & $<0.001$ & $<0.001$ & $<0.001$ & $<0.001$ & $<0.001$ \\
\hline & Root & $1 \pm 1$ & $2 \pm 3$ & $0.3 \pm 0.3$ & $1 \pm 1$ & $0.06 \pm 0.04$ & $4 \pm 5$ \\
\hline $\mathrm{CD}$ & Mycelium & nd & $0.5 \pm 0.1$ & $0.8 \pm 0.1$ & nd & $0.5 \pm 0.3$ & $1.8 \pm 0.3$ \\
\hline & Medium & nd & $27 \pm 1$ & nd & nd & nd & $27 \pm 1$ \\
\hline & $p$-value & $<0.001$ & $<0.001$ & $<0.001$ & $<0.001$ & $<0.001$ & $<0.001$ \\
\hline $\mathrm{CP} \times \mathrm{CE}$ & $p$-value & $<0.001$ & $<0.001$ & $<0.001$ & $<0.001$ & $<0.001$ & $<0.001$ \\
\hline
\end{tabular}


${ }^{a}$ Results are reported as mean value of each culture element (CE) over the different coculture periods (CP) as well as mean value of all elements within each co-culture period. 

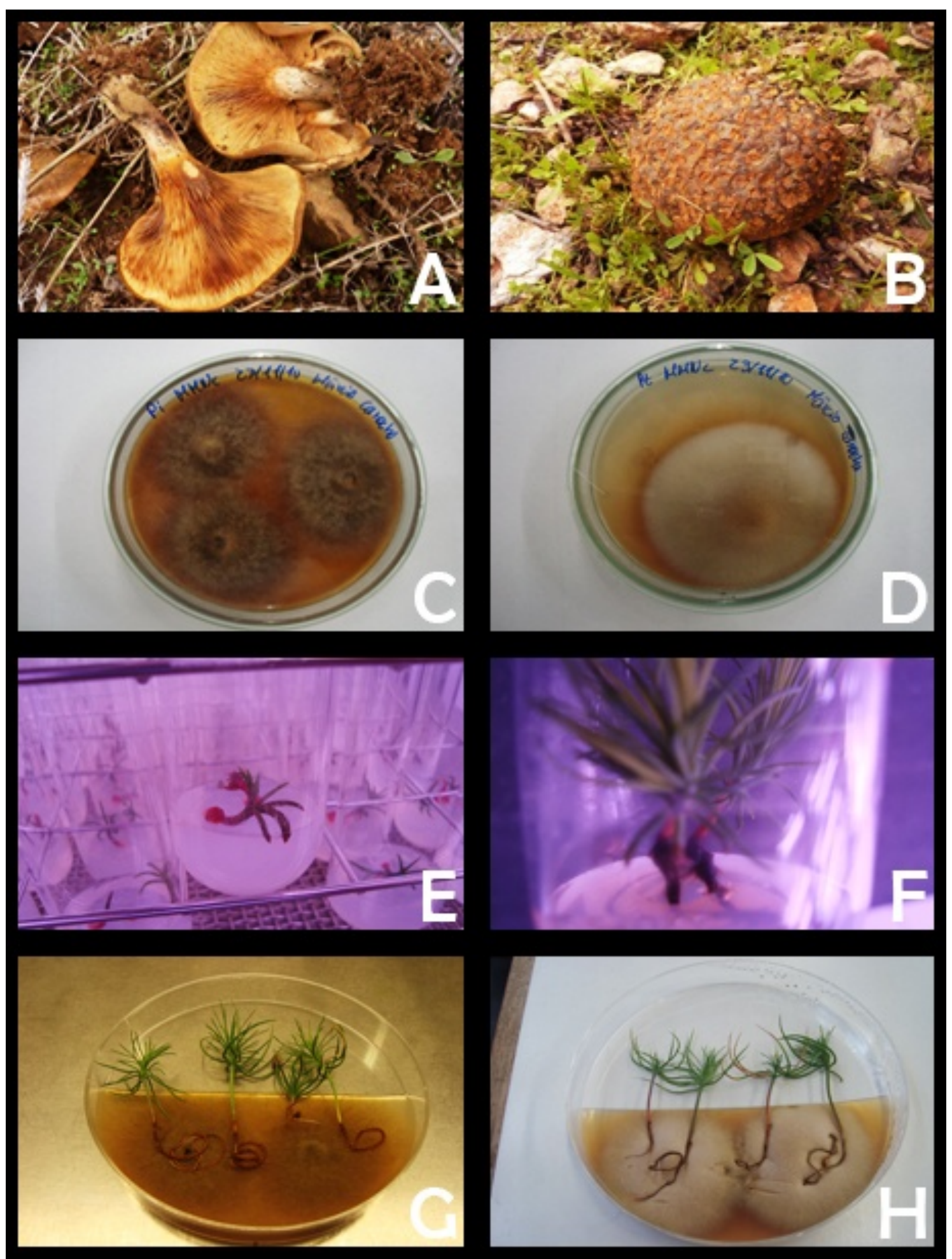

Figure 1. A. Paxillus involutus fruiting body; B. Pisolithus arhizus fruiting body; C. Paxillus involutus mycelium; D. Pisolithus arhizus mycelium; E. Pinus pinaster seeds 
under germination; F. Pinus pinaster seedlings; G - Paxillus involutus mycelium-Pinus pinaster seedlings mycorrhizal induction in vitro; H. Pisolithus arhizus myceliumPinus pinaster seedlings mycorrhizal induction in vitro. 


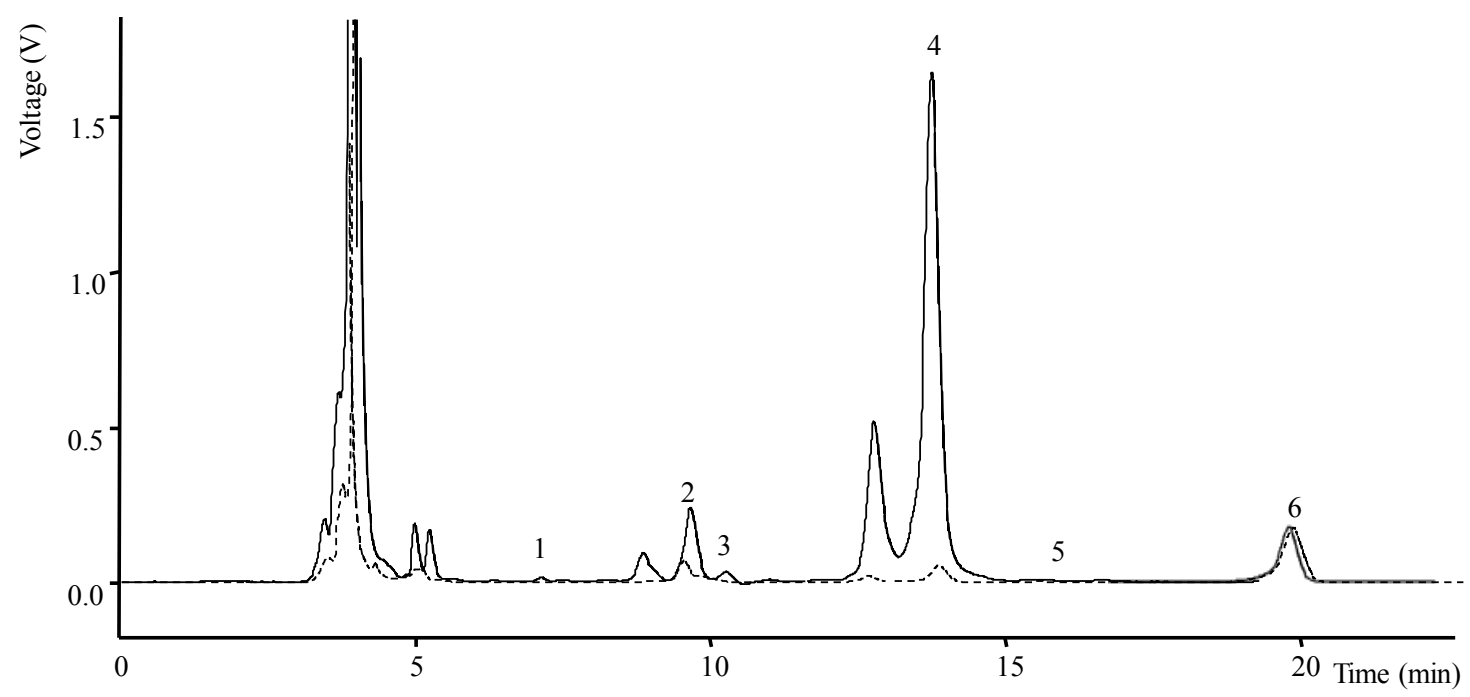

(A)

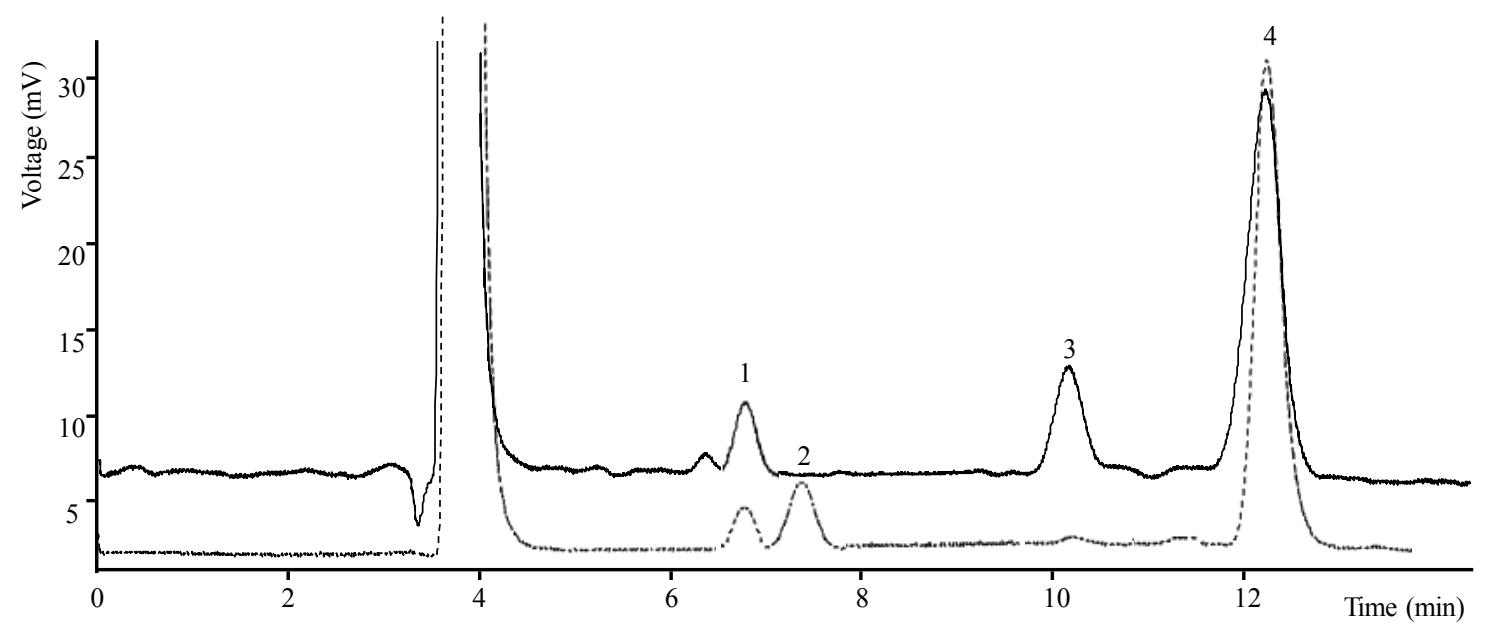

(B)

Figure 2. A. Tocopherols profile of Pisolithus arhizus (-) and Paxillus involutus (--) mycelium in co-culture with Pinus pinaster root for 24 h (1- $\alpha$-tocopherol; 2- BHT; 3 $\beta$-tocopherol; 4- $\gamma$-tocopherol; 5- $\delta$-tocopherol; 6- IS). B. Sugars profile of Pisolithus arhizus (-) and Paxillus involutus (--) mycelium in co-culture with Pinus pinaster root for 72 h (1- glucose; 2- mannitol; 3- trehalose; 4- IS). 


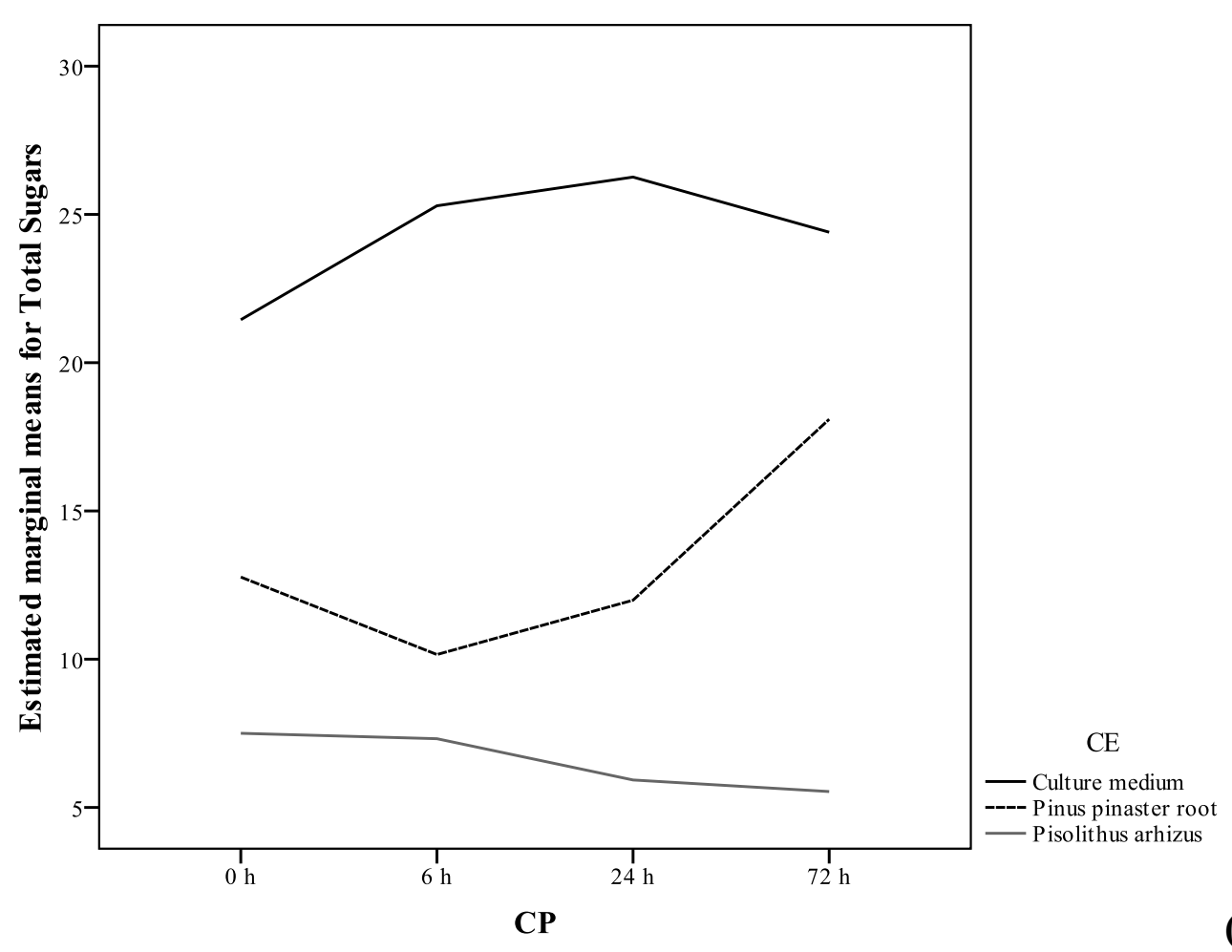

(A)

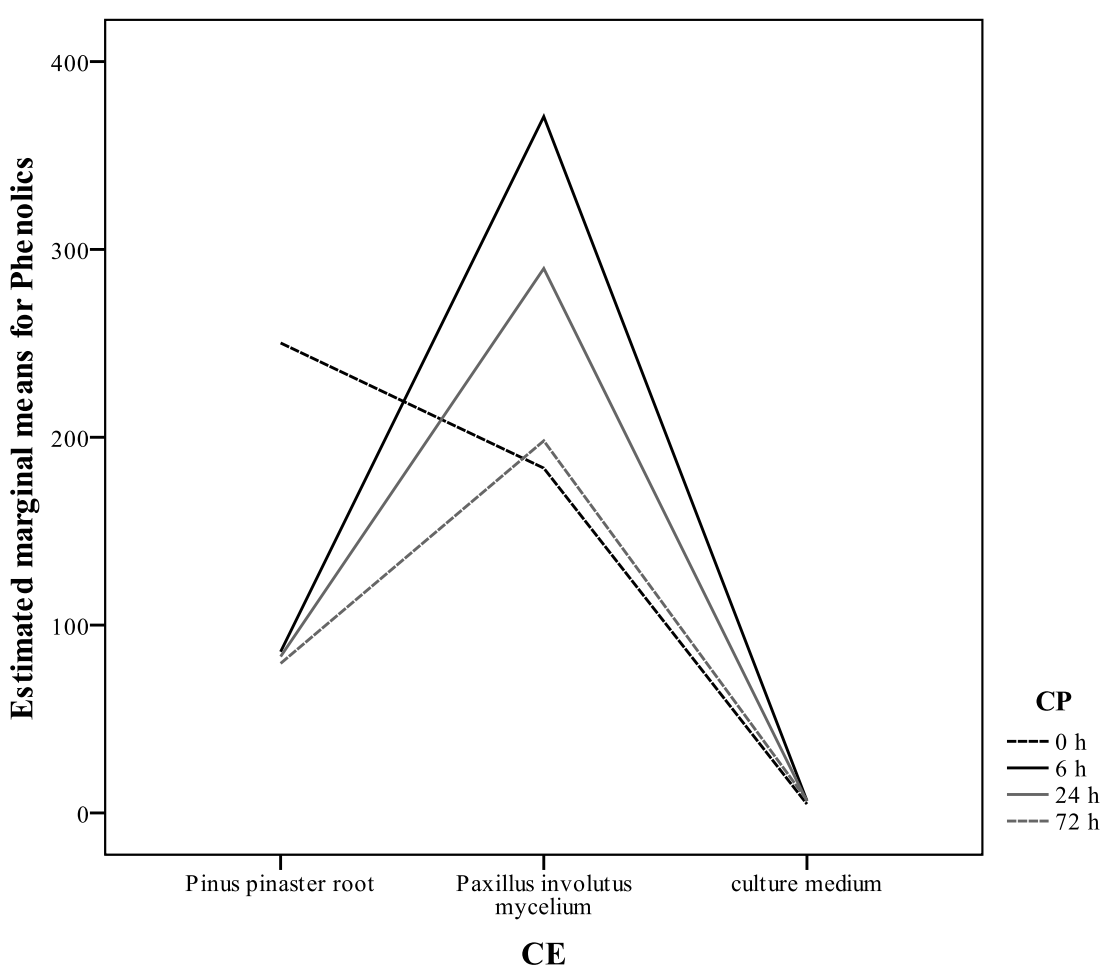

(B)

Figure 3. Estimated marginal means for total sugars contents (A) on different co-culture elements (CE) and for phenolic contents (B) on different co-culture periods (CP). 

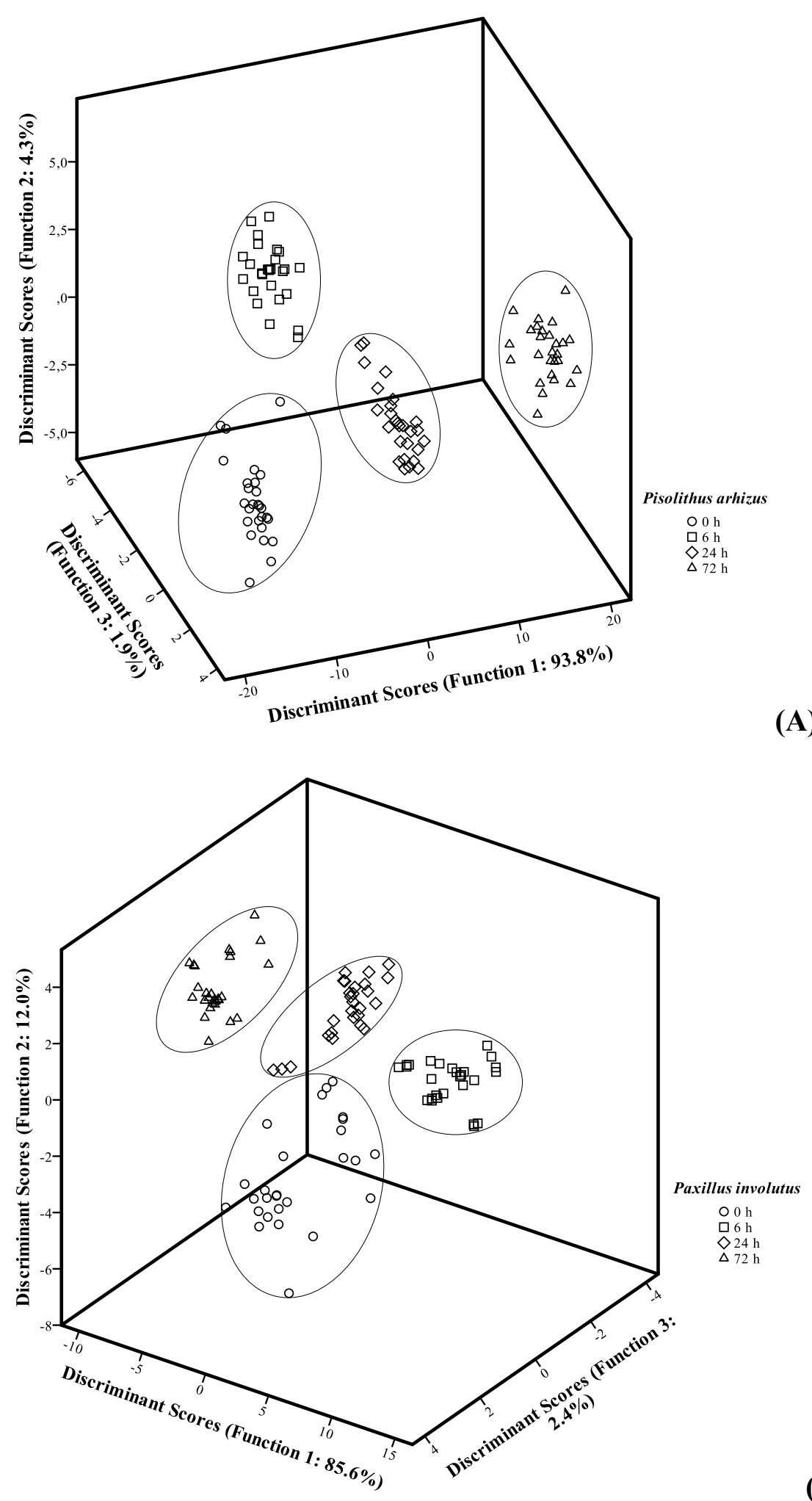

(A)

Figure 4. Canonical analysis of co-culture (A: Pisolithus arhizus; B: Paxillus involutus) periods based on all the assayed parameters. 


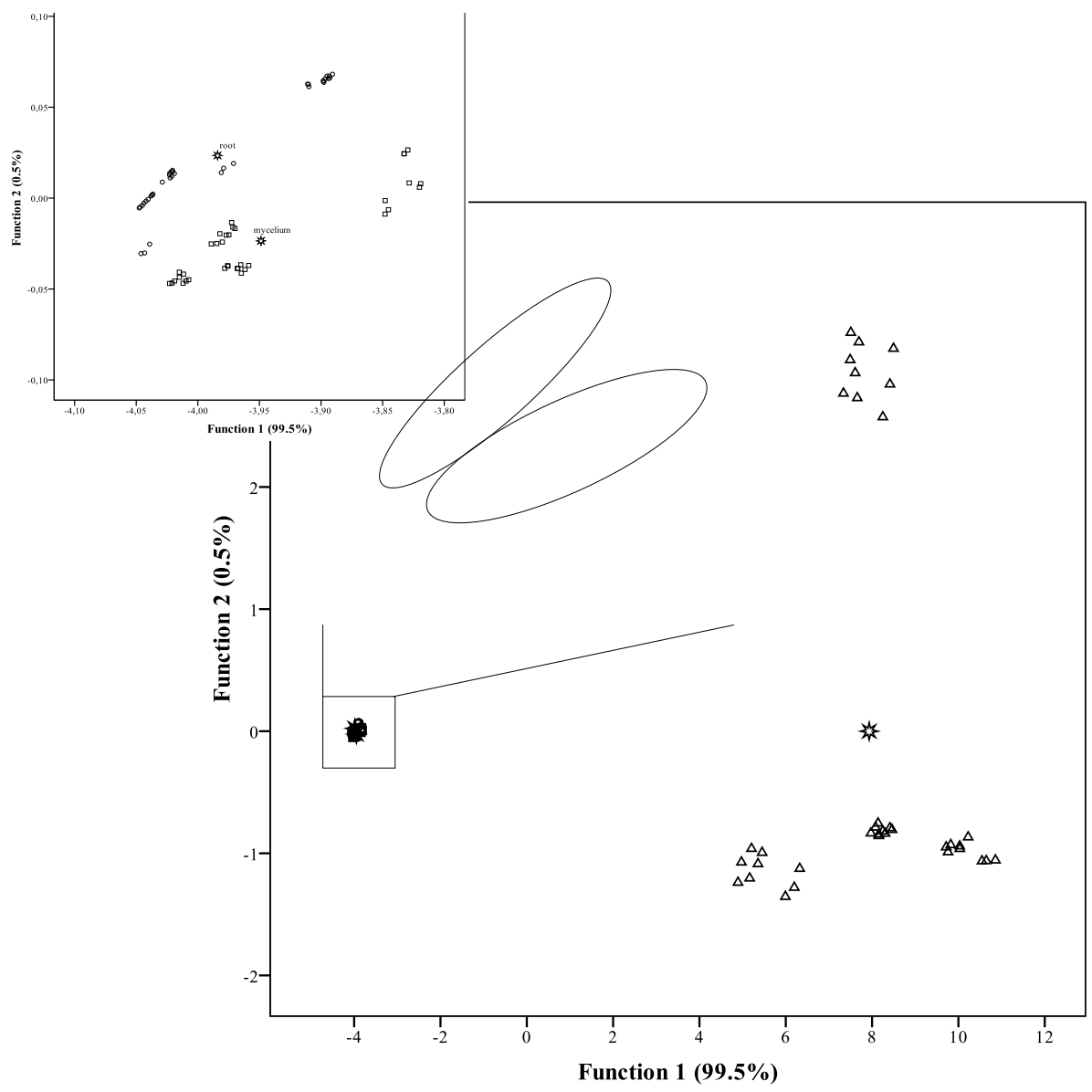

Co-culture element

- Pinus pinaster root

$\Delta$ Culture medium

Group Centroid

(A)

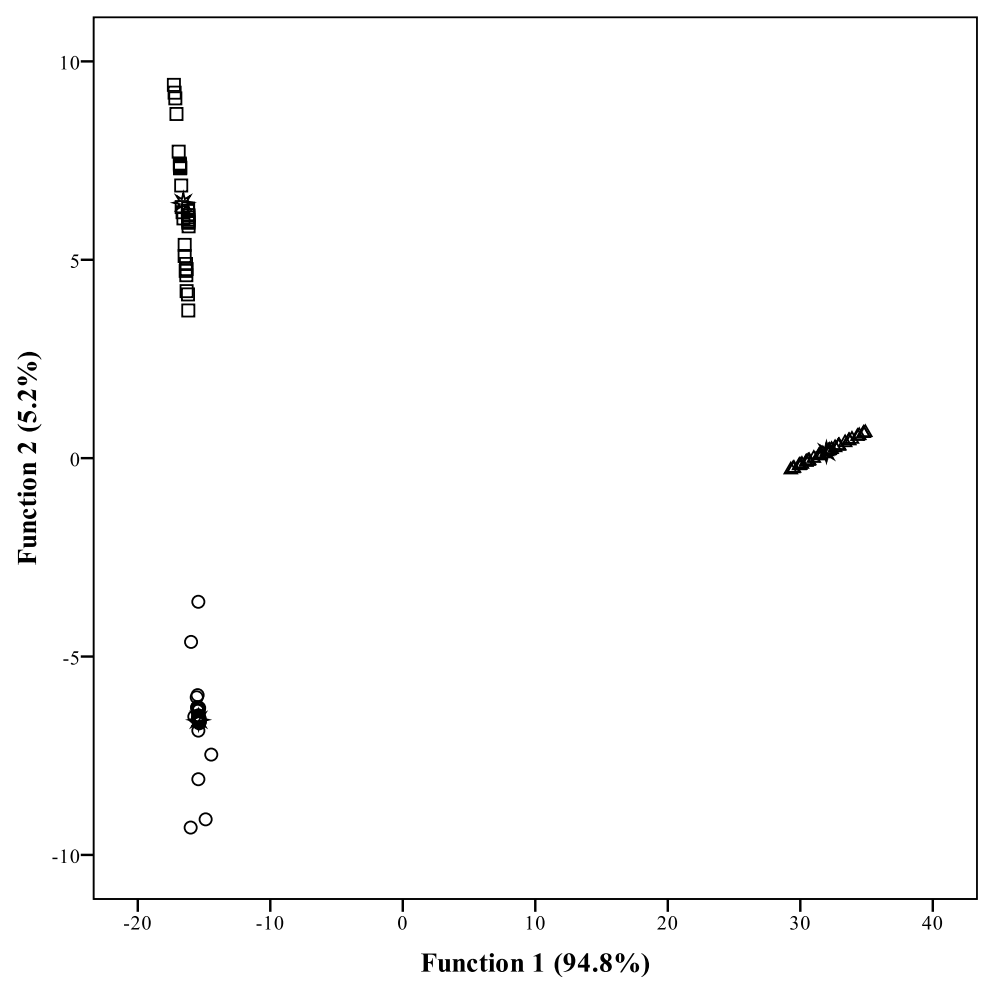

Paxillus involutus

O Pinus pinaster root
$\square$ Paxillus involutus $\Delta$ Culture medium Group Centroid

(B)

Figure 5. Canonical analysis of Pisolithus arhizus-Pinus pinaster co-culture elements based on antioxidant activity assays $\mathrm{EC}_{50}$ values (A) and of Paxillus involutus-Pinus 
pinaster co-culture elements based on sugars contents (B). Due to the proximity of $P$. pinaster root and P. arhizus mycelium, an expansion in an adequate scale was included. 